23

\title{
Исследование спектральных характеристик оптико-абсорбционного газоанализатора контроля фреонов в воздушной среде
}

\author{
(ㄱ Л.А. Конопелько ${ }^{1}$, Е.П. Тюрикова ${ }^{1}$, Ю.Н. Снытко ${ }^{2, q}$ \\ ${ }^{1}$ Университет ИТМО, \\ 197101 Санкт-Петербург, Россия \\ 2 ФГУП „СПО „Аналитприбор“, \\ 214031 Смоленск, Россия \\ ฯ e-mail: snytko72@mail.ru
}

Поступила в редакцию 19.11.2019 г.

В окончательной редакции 05.02.2020 г.

Принята к публикации 07.02.2020 г.

Представлена оптическая схема оптико-абсорбционного газоанализатора, оптимизированная для измерения содержания фреонов. Разработан и исследован излучатель с заданным максимумом спектральной плотности энергетической светимости в диапазоне от 8 до $10 \mu \mathrm{m}$ с опорным каналом 9.5 $\mu \mathrm{m}$, порогом измерения 1 ppm. Разработана конструкция системы интерференционных фильтров.

Ключевые слова: газоанализатор, фреон, абсорбционная спектроскопия, пироприемник.

DOI: $10.21883 /$ OS.2020.05.49329.308-19

\section{Введение}

Термином фреоны обозначают группу, объединяющую газообразные вещества и низкокипящие жидкости. Основная масса фреонов малотоксична, чем и обусловлена их повсеместная распространенность. Попадая в организм, они не метаболизируют с образованием ядовитых промежуточных продуктов, а выводятся в неизмененном виде. Токсичностью обладают продукты горения хладоагентов при нагревании их свыше $250-400^{\circ} \mathrm{C}$. К таким относятся, например, продукты горения фреона-22 тетрафторэтилен, сосудистый яд, обладающий нейрои нефротоксическим действием, и фосген - мощное отравляющее вещество, вызывающее отек легких.

Применение фреонов в промышленности имеет два ярко выраженных направления: технологическое (кондиционеры и холодильное оборудование) и применение в качестве пламягасителя (в автоматических системах пожаротушения). Основными стандартами в области применения фреонов являются ГОСТ Р 12.2.142-99 (ИСО 5149-93) „Системы холодильные холодопроизводительностью свыше 3.0 кВт“, и ГОСТ 15899-93 „1,1,2,2-тетрафтордибромэтан (хладон 114В2)“. Наиболее часто применяемые в промышленности фреоны и их основные физические характеристики приведены в табл. 1 [1,2].

При выборе метода измерения и конструкции разрабатываемого газоанализатора были рассмотрены литературные данные $[3,4]$. Для контроля содержания фреонов в настоящее время используются электрохимические, полупроводниковые и оптико-абсорбционные газоанализаторы. Характеристики различных типов существующих газоанализаторов и разработанного нами газоанализатора приведены в табл. 2.
Принцип действия электрохимических газоанализаторов основан на измерении сопротивления (электропроводности), напряжения или силы тока в растворах электролитов при их взаимодействии с анализируемым газом. Анализатор, использующий электрохимические датчики, обладает низкими селективностью и быстродействием и требует периодической корректировки показаний по мере расхода ресурса электрохимической ячейки. Электрохимическая ячейка теряет работоспособность при влажности менее $45 \%$ и перегрузках.

В основе работы полупроводниковых газоанализаторов лежит изменение проводимости чувствительного слоя при хемосорбции на его поверхности молекул химически активных газов. Селективность анализа достигается варьированием состава чувствительного слоя и его температуры (при помощи встроенного нагревателя). Анализаторы на полупроводниковых сенсорах обладают высокой погрешностью измерения, низким ресурсом, данный тип не пригоден для измерения малых концентраций фреонов и применяется в основном в качестве течеискателей фреонов.

Оптико-абсорбционные газоанализаторы основаны на использовании зависимости изменения того или иного оптического свойства анализируемой газовой смеси от изменения концентрации измеряемого компонента. Анализаторы, основанные на оптической абсорбционной спектроскопии, имеют недостаточную селективность (при наличии высоких концентраций неизмеряемых компонентов) и неустойчивы к качке и наклонам, что ограничивает их применение для контроля фреонов на судах.

В работе [5] показано, что фреоны имеют интенсивные полосы поглощения в диапазоне спектра 7.5-10 $\mathrm{m}$. Спектры поглощения фреонов 114В2, 227еa, 12, 22, 
Таблица 1. Основные физические характеристики фреонов

\begin{tabular}{l|c|c|c|c|c|c}
\hline $\begin{array}{c}\text { Обозначение } \\
\text { химическая } \\
\text { формула) }\end{array}$ & $\begin{array}{c}\text { Относительная } \\
\text { молекулярная } \\
\text { масса }\end{array}$ & $\begin{array}{c}\text { Точка кипения } \\
\text { при атмосферном } \\
\text { давлении, } \\
{ }^{\circ} \mathrm{C}\end{array}$ & $\begin{array}{c}\text { Температура } \\
\text { замерзания, } \\
{ }^{\circ} \mathrm{C}\end{array}$ & $\begin{array}{c}\text { Критическая } \\
\text { температура, } \\
{ }^{\circ} \mathrm{C}\end{array}$ & $\begin{array}{c}\text { ПДК рабочей } \\
\text { зоны, } \\
\mathrm{mg} / \mathrm{m}^{3}\end{array}$ & $\begin{array}{c}\text { ПдК жилой } \\
\text { зоны, } \\
\mathrm{mg} / \mathrm{m}^{3}\end{array}$ \\
\hline $227 \mathrm{ea}\left(\mathrm{C}_{3} \mathrm{~F}_{7} \mathrm{H}\right)$ & 170.03 & -16.4 & -148.5 & 103.5 & 3000 & - \\
\hline $\begin{array}{l}114 \mathrm{~B} 2 \\
\left(\mathrm{C}_{2} \mathrm{Br}_{2} \mathrm{~F}_{4}\right)\end{array}$ & 259.82 & 47.3 & -110.5 & 214.4 & 1000 & - \\
\hline $12\left(\mathrm{CCl}_{2} \mathrm{~F}_{2}\right)$ & 120.9 & -29.8 & -158 & 112 & 3000 & 100 \\
\hline $22\left(\mathrm{CHClF}_{2}\right)$ & 86.5 & -40.8 & -160 & 96 & 3000 & 100 \\
\hline $134 \mathrm{~A}\left(\mathrm{C}_{2} \mathrm{H}_{2} \mathrm{~F}_{4}\right)$ & 102.031 & -26.5 & -103.3 & 101 & 3000 & -
\end{tabular}

Таблица 2. Сравнение характеристик различных типов газоанализаторов

\begin{tabular}{|c|c|c|c|c|c|}
\hline \multirow[t]{2}{*}{ № } & \multirow[t]{2}{*}{ Параметр } & \multicolumn{4}{|c|}{ Значения } \\
\hline & & Разработанный & Оптический & $\begin{array}{c}\text { Электро- } \\
\text { химический }\end{array}$ & $\begin{array}{c}\text { Полупро- } \\
\text { водниковый }\end{array}$ \\
\hline 1 & Диапазон измерений, ppm & $0-463$ & $0-1000$ & $0-100$ & $20-300$ \\
\hline 2 & Порог измерения, ppm & 1 & 1 & 1 & 20 \\
\hline 3 & Общая погрешность измерений, \% & 15 & 15 & 15 & 20 \\
\hline 4 & Дрейф показаний, \% & 5 & 7 & 15 & 10 \\
\hline 5 & $\begin{array}{c}\text { Перекрестная чувствительность } \\
\text { к другим газам }\end{array}$ & Отсутствует & Нет данных & $\begin{array}{c}\mathrm{CO}-5 \% \\
\mathrm{CO}_{2}-5 \% \\
\mathrm{H}_{2}-5 \% \\
\mathrm{H}_{2} \mathrm{~S}-5 \% \\
\mathrm{NH}_{3}-5 \% \\
\mathrm{C}_{2} \mathrm{H}_{5} \mathrm{OH}-5 \% \\
\mathrm{He}-5 \% \\
\mathrm{CH}_{3} \mathrm{COCH}_{3}-5 \%\end{array}$ & $\begin{array}{c}\mathrm{CO}-15 \% \\
\mathrm{H}_{2}-10 \% \\
\mathrm{H}_{2} \mathrm{~S}-10 \% \\
\mathrm{C}_{2} \mathrm{H}_{5} \mathrm{OH}-15 \% \\
\mathrm{He}-5 \% \\
\mathrm{CH}_{3} \mathrm{COCH}_{3}-20 \%\end{array}$ \\
\hline 6 & Энергопотребление, W & 50 & 45 & 150 & 5 \\
\hline 7 & Габариты, mm & $340 \times 315 \times 223$ & $\begin{array}{c}\text { БИ } \\
275 \times 252 \times 140 \\
\text { Датчик } \\
130 \times 114 \times 68\end{array}$ & $\begin{array}{c}\text { БПХ } \\
340 \times 355 \times 315 \\
\text { БПН } \\
280 \times 420 \times 240\end{array}$ & $94 \times 130 \times 57$ \\
\hline 8 & Macca, $\mathrm{kg}$ & 25 & 4 & 36 & 0.5 \\
\hline
\end{tabular}

134А приведены на рис. 1. Регистрация спектра поглощения фреонов с концентрацией $350-800 \mathrm{mg} / \mathrm{m}^{3}$ проводились спектрофотометром с длиной кюветы $100 \mathrm{~mm}$. На длине волны $4.26 \mu \mathrm{m}$ можно видеть линию поглощения $\mathrm{CO}_{2}$. Из анализа приведенных на рис. 1 спектров следует, что измерения необходимо проводить в диапазоне длин волн от 8 до $10 \mu \mathrm{m}$, а полосу поглощения на длине волны $9.5 \mu \mathrm{m}$ целесообразно использовать в качестве опорной для компенсации внешних воздействий и загрязнения оптики.

Дополнительно сравним характеристики разработанного нами газоанализатора и оптико-абсорбционного газоанализатора, разработанного РТУ МИРЭА (табл. 3). Новые технические решения по определению содержания фреона методом абсорбционной спектроскопии, реализованные в разработанном газоанализаторе, позволяют проводить измерения с селективностью и чувствительностью, большими, чем существующие газоанализаторы. Из вышесказанного можно сделать вывод о востребованности оптико-абсорбционного газоанализатора, обладающего высокой селективностью, относительно невысокой стоимостью и большим ресурсом работы. 


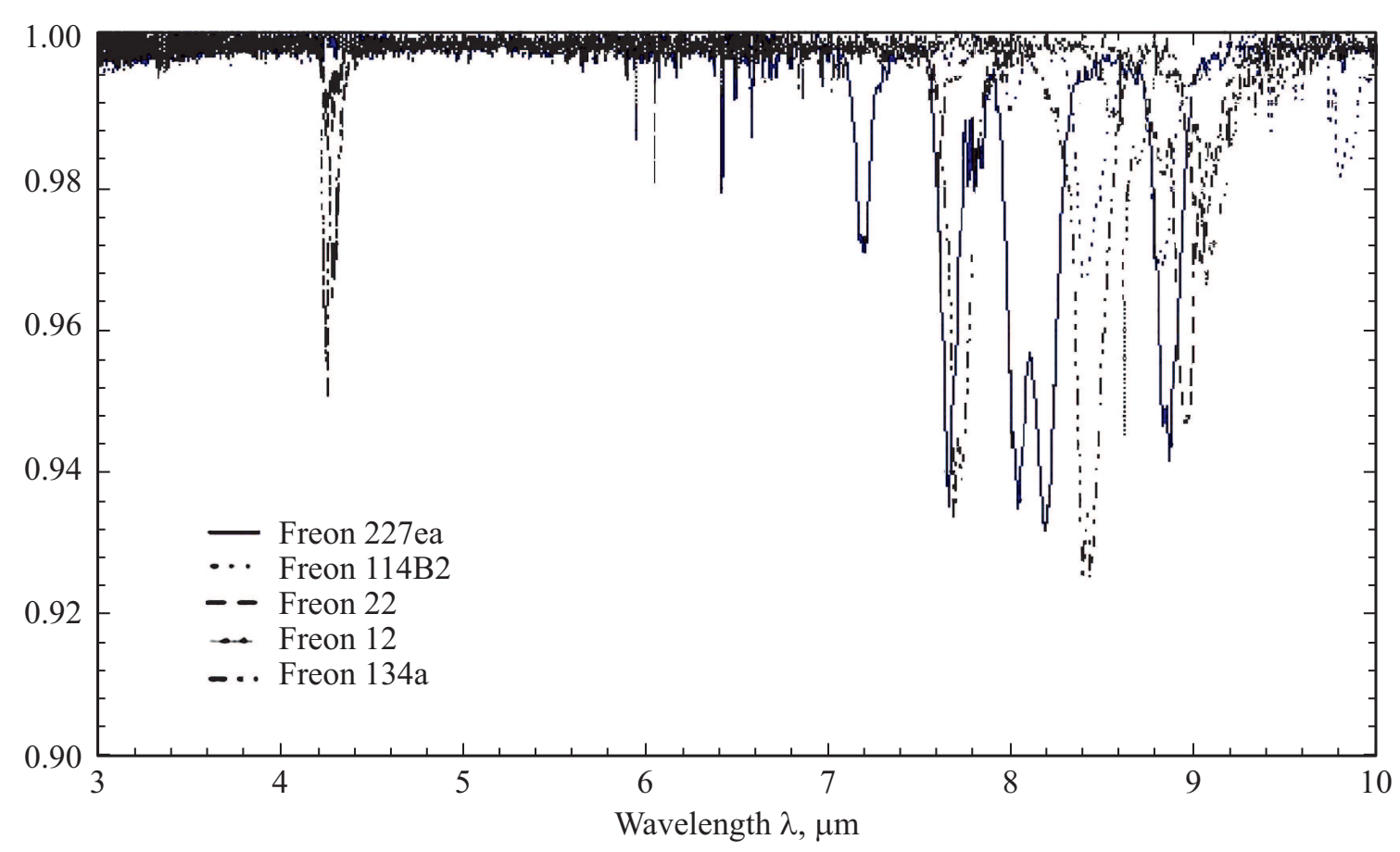

Рис. 1. Спектр поглощения фреонов в диапазоне 3-10 $\mu \mathrm{m}$.

\section{Принцип работы оптико-абсорбционного газоанализатора}

Структурная схема разработанного оптико-абсорбционного газоанализатора представлена на рис. 2 (структурная схема с одним рабочим каналом). В указанной схеме ИК излучение, формируемое излучателем, направляется в рабочую камеру, газовая смесь в рабочей камере модулируется давлением с периодом $2.7 \mathrm{~s}$. Модуляция давлением исключает влияние внешних воздействий факторов на показания газоанализатора при отсутствии в рабочей камере целевого компонента (на нулевые показания). Проходя кювету и попадая на приемники оптического излучения (ПОИ), поток $\Phi$ ослабляется в соответствии с коэффициентами $K_{\Phi}, K_{X \Phi}, K_{P W}$. Избирательность измерений достигается применением интерференционных фильтров в опорном и рабочем каналах $\left(K_{\Phi 1}\right.$ и $\left.K_{\Phi 2}\right)$. Длина волны пропускания интерференционного фильтра опорного канала равна $9.5 \mu \mathrm{m}$. На этой длине волны отсутствуют линии поглощения фреонов.

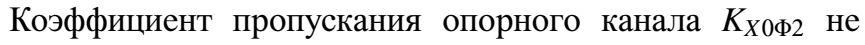
изменяется при изменении содержания целевого компонента в рабочей камере. Коэффициенты преобразования потока ИК излучения в электрический сигнал $K_{P W 1}$, $K_{P W 2}$ являются характеристиками ПОИ и при использовании пироприемников имеют достаточно близкие значения. Результирующий сигнал преобразуется в выходной параметр $X^{*}$ пропорционально $K_{W X}$. Уравнение измерения концентрации $X^{*}$ в соответствии с рис. 1
Таблица 3. Сравнение характеристик оптико-абсорбционных газоанализаторов

\begin{tabular}{|c|c|c|c|}
\hline № & Параметр & Разработанный & $\begin{array}{l}\text { Газоанализатор } \\
\text { РТУ МИРЭАМ1 }\end{array}$ \\
\hline 1 & $\begin{array}{l}\text { Диапазон } \\
\text { измерений }\end{array}$ & $0-463 \mathrm{ppm}$ & $0-100000 \mathrm{ppm}$ \\
\hline 2 & Порог измерения & $1 \mathrm{ppm}$ & $10000 \mathrm{ppm}$ \\
\hline 3 & $\begin{array}{l}\text { Общая погрешность } \\
\text { измерений }\end{array}$ & $15 \%$ & $20 \%$ \\
\hline 4 & Дрейф показаний & $5 \%$ & $8 \%$ \\
\hline 5 & $\begin{array}{l}\text { Перекрестная } \\
\text { чувствительность } \\
\text { к другим газам }\end{array}$ & Отсутвует & Нет данных \\
\hline 6 & Энергопотребление & $50 \mathrm{~W}$ & $100 \mathrm{~W}$ \\
\hline 7 & Габариты, mm & $340 \times 315 \times 223$ & $\begin{array}{c}\text { БППС } \\
250 \times 150 \times 100 \\
\text { Датчик } \\
360 \times 210 \times 200\end{array}$ \\
\hline 8 & Macca, kg & 25 & 13 \\
\hline 9 & $\begin{array}{l}\text { Дополнительное } \\
\text { оборудование } \\
\text { для работы }\end{array}$ & $\begin{array}{c}\text { Не } \\
\text { требуется }\end{array}$ & $\begin{array}{c}\text { Вакуумный } \\
\text { насос }\end{array}$ \\
\hline
\end{tabular}




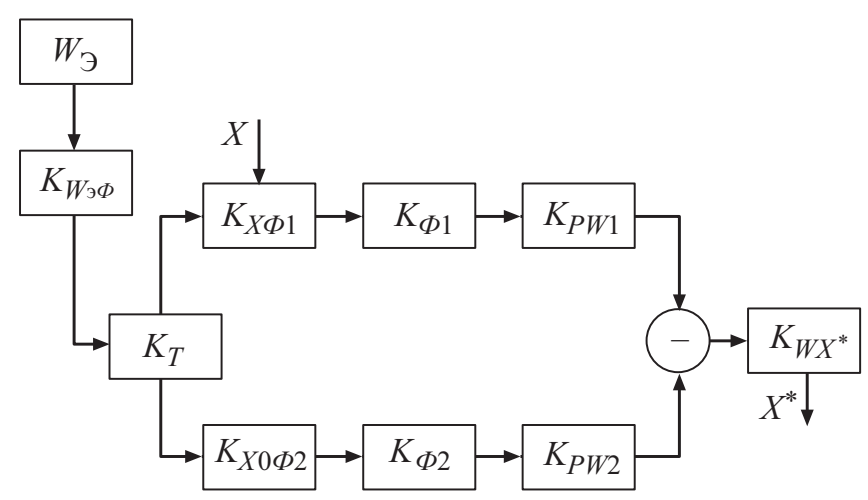

Рис. 2. Структурная схема оптико-абсорбционного газоанализатора: $W_{\ni}$ - мощность источника питания излучателя; $K_{W_{\ni} \Phi}-$ коэффициент преобразования электрической энергии в поток ИК излучения; $K_{T}$ - коэффициент, характеризующий пропускание рабочей камеры; $K_{\Phi 1}, K_{\Phi 2}-$ коэффициенты пропускания потока ИК излучения интерференционными филь-

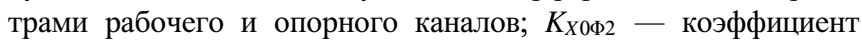
пропускания опорного канала; $K_{X \Phi 1}-$ коэффициент пропускания рабочего канала $K_{X \Phi 1}=e^{-l X K}$ (где $K-$ интегральный коэффициент поглощения, $l-$ длина рабочей кюветы, $X-$ концентрация измеряемого компонента); $K_{P W 1}, K_{P W 2}-$ коэффициенты преобразования потока ИК излучения в электрический сигнал $W ; K_{W X^{*}}$ - коэффициент преобразования разности электрических сигналов в оценку концентрации измеряемого компонента $X^{*}$.

можно записать в следующем виде:

$W_{\ni} K_{W \ni \oint} K_{T}\left(K_{\Phi 1} K_{X \Phi 1} X K_{P W 1}-K_{\Phi 2} K_{X 0 \Phi 1} K_{P W 2}\right) K_{W X}=X^{*}$.

Выражение (1) можно разделить на две части.

1) Разность в скобках при $X=1$ (целевой компонент отсутствует) описывает нулевые показаний газоанализатора. Для достижения стабильности нулевых показаний с помощью настроечных операций достигается равенство произведения коэффициентов $K_{\Phi 1} K_{X \Phi 1} K_{P W 1}$ и $K_{\Phi 2} K_{\Phi} K_{P W 2}$ при отсутствии целевого компонента. При этом максимальная чувствительность газоанализатора будет определяться плотностью интерференционных фильтров, с помощью которых устраняется влияние неизмеряемых компонентов (атмосферная влага и двуокись углерода, содержащиеся в воздухе).

2) Множители $W_{\ni}, K_{W_{\ni} \Phi}, K_{T}, K_{W X}$ в общем виде отвечают за чувствительность газоанализатора.

При достижении стабильных нулевых показаний и отсутствии влияния неизмеряемых компонентов возможно добиться максимальной чувствительности газоанализатора, повышая соответствующим образом указанные множители.

$W_{\text {э }}$ - повышением мощности источника питания излучателя (ограничена тепловым режимом газоанализатора);

$K_{W_{9} \Phi}$ - повышение коэффициента преобразования электрической энергии в поток ИК излучения дости- гается смещением максимума спектральной плотности энергетической светимости в диапазон от 8 до $10 \mu \mathrm{m}$;

$K_{T}$ - повышение коэффициента пропускания достигается путем полировки поверхности рабочей камеры;

$K_{W X}$ - повышение коэффициента усиления электрического усилителя сигналов пироприемников имеет ограничения, поскольку усиливаются как полезный сигнал, так и шумы ПОИ, вследствие чего повышать усиление возможно до момента превышения шумов над требуемой минимальной ценой деления шкалы газоанализатора.

Для достижения высокой избирательности и стабильности показаний оптико-абсорбционного газоанализатора фреонов требуется:

- обеспечить максимум спектральной плотности энергетической светимости ИК излучателя в длинноволновой области от 8 до $10 \mu \mathrm{m}$, используя приемник ИК излучения с высокой чувствительностью в вышеуказанной области;

- создать систему интерференционных фильтров для обеспечения лучшей избирательности;

- создать в газоанализаторе многоканальную оптическую схему для обеспечения контроля технологического и огнегасящего фреона в одном помещении.

Далее рассмотрим основные технические решения, реализованные в разработанном оптико-абсорбционном газоанализаторе, позволившие получить более высокие избирательность и стабильность показаний по сравнению с существующими аналогами.

\section{Спектральные измерения элементов оптического канала}

В качестве элементов, обеспечивающих селективность измерения содержания фреонов, необходимо применить узкополосные интерференционные фильтры [6]. Интерференционный фильтр позволяет увеличить отношение сигнал/шум, увеличивая тем самым чувствительность и избирательность оптико-электронного при-

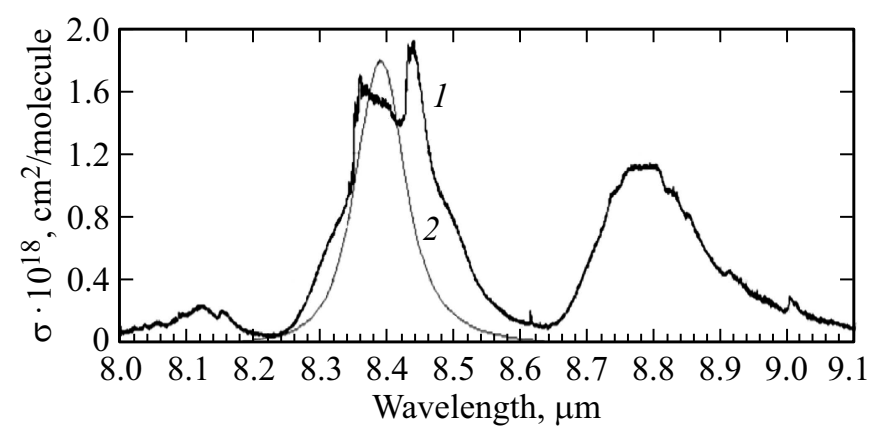

Рис. 3. Спектральный показатель поглощения фреона 114B2 $\left(1, \mathrm{~cm}^{2} /\right.$ molecule $)$ и спектральный показатель пропускания интерференционного фильтра, установленного в рабочий канал 1 (2, arb. units). 


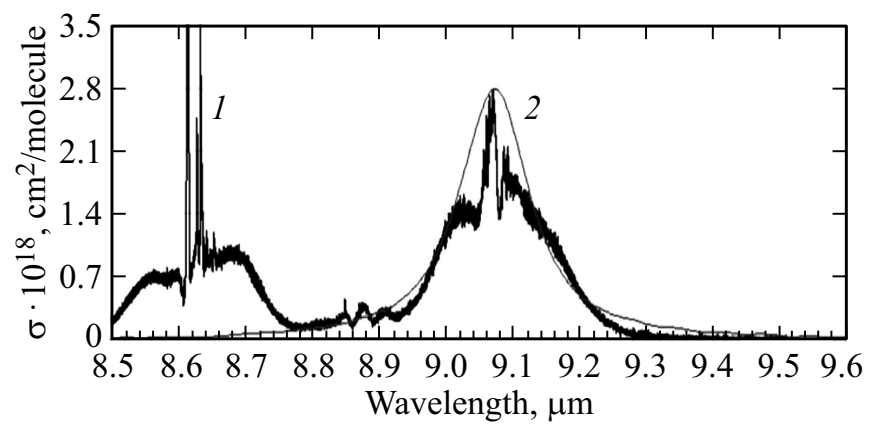

Pис. 4. Спектральный показатель поглощения фреона 22 $\left(1, \mathrm{~cm}^{2} /\right.$ molecule) и спектральный показатель пропускания интерференционного фильтра, установленного в рабочий канал 2 (2, arb. units).

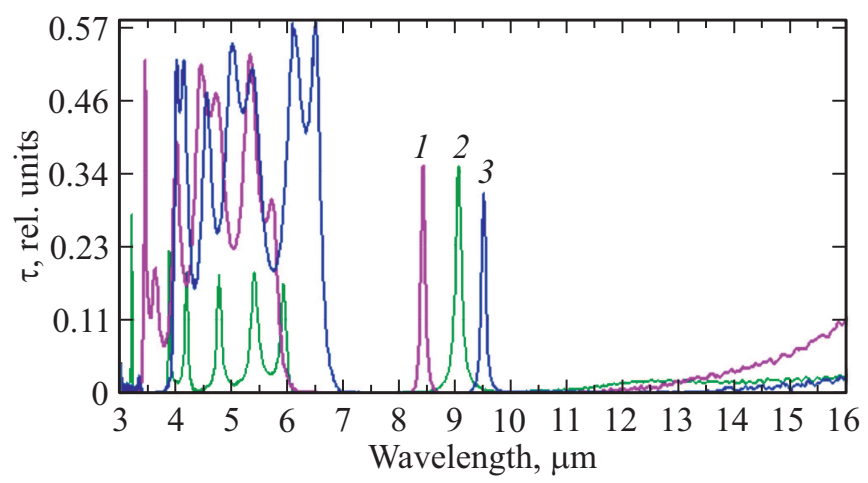

Рис. 5. Относительный спектральный коэффициент пропускания интерференционных фильтров: 1 - фреон 114В2, 2 - фреон 22, 3 - опорный канал.

бора, несмотря на общее ослабление полезного сигнала. Спектральный коэффициент пропускания интегральных фильтров должен соответствовать спектральным показателям поглощения фреонов как можно более точно. Примеры такого соответствия для фреона 114B2 и фреона 22 приведены на рис. 3 и 4 соответственно.

Для одновременного измерения содержания двух типов фреонов необходимо предусмотреть два рабочих канала измерения и один опорный канал. Относительный спектральный коэффициент пропускания интерференционных фильтров в рабочих и опорном каналах приведен на рис. 5. Анализируя рис. 5, можно сделать вывод, что интерференционные фильтры имеют нежелательный фон, т.е. пропускают некоторую часть излучения в области более $11 \mu \mathrm{m}$. Также имеют место побочные максимумы в области менее $7 \mu \mathrm{m}$, которые необходимо удалить путем наложения фильтров разных типов. Для этого на входе в блок приемников требуется установить отрезающий фильтр и пластину флюорита. Учтя спектральные коэффициенты пропускания интерференционных фильтров (рис. 5), отрезающего фильтра и пластины флюорита, получим спектральную плотность энергетической светимости отфильтрованного потока излучения, падающего на ПОИ (рис. 6). Сопоставляя рис. 5 и 6, можно оценить подавление паразитной засветки ПОИ при установке отрезающего фильтра и пластины флюорита: в области более $11 \mu \mathrm{m}$ - в 50 раз, а в области менее $7 \mu \mathrm{m}$ - в 25 раз. Дальнейшее подавление паразитной засветки возможно при использовании излучателя, имеющего максимум спектральной плотности энергетической светимости в области от 8 до $10 \mu \mathrm{m}$.

\section{Выбор материала излучателя оптико-абсорбционного газоанализатора}

Для получения максимума спектральной плотности энергетической светимости излучателя в области от 8 до $10 \mu \mathrm{m}$ необходим материал, имеющий следующие оптические свойства [7]:

- пропускающий излучение в области менее 6-7 $\mu \mathrm{m}$;

- поглощающий излучение в области свыше 7-8 $\mu \mathrm{m}$.

Из материалов с подходящими оптическими свойствами рассмотрим следующие: $\mathrm{Al}_{2} \mathrm{O}_{3}$ (лейкосапфир), $\mathrm{LiF}$ (фтористый литий), $\mathrm{CaF}_{2}$ (дифторид кальция). Рас-

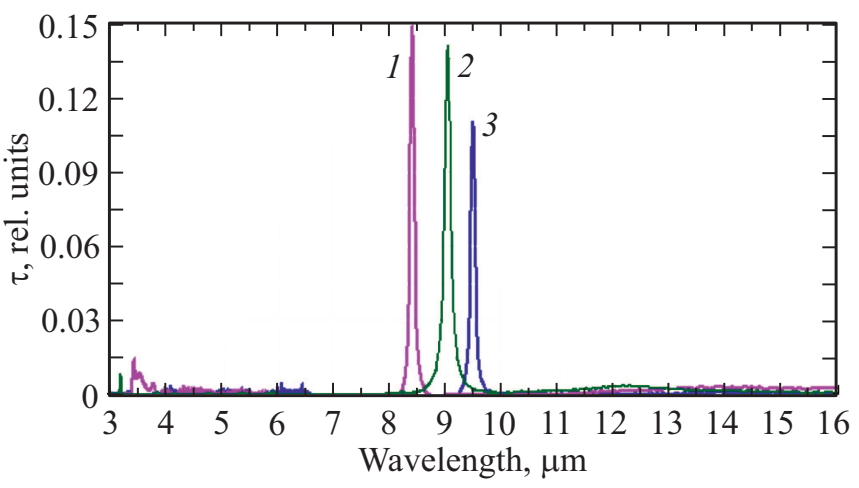

Рис. 6. Относительный спектральный коэффициент пропускания всех оптических элементов оптического канала: 1 - фреон 114В2, 2 - фреон 22, 3 - опорный канал.

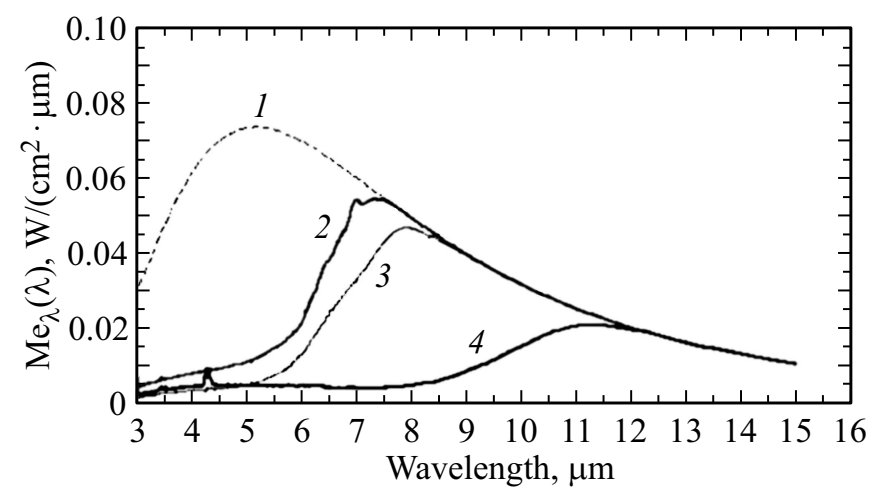

Pис. 7. Спектральная плотность энергетической светимости при температуре $290^{\circ} \mathrm{C}: 1-$ черное тело, $2-\mathrm{Al}_{2} \mathrm{O}_{3}, 3-\mathrm{LiF}$, $4-\mathrm{CaF}_{2}$. 
четные спектральные плотности энергетической светимости при температуре $290^{\circ} \mathrm{C}$ всех трех материалов в сравнении со спектральной плотностью энергетической светимости черного тела приведены на рис. 7. Сопоставление кривых на рис. 7 позволяет сделать вывод о значительном (на 70-80\%) подавлении нежелательного фона в области 3-6 $\mu \mathrm{m}$. Смещение максимума спектральной плотности энергетической светимости в область от 8 до $10 \mu \mathrm{m}$ обеспечивает требуемую избирательность измерений содержания фреонов. Материалом, имеющим максимум спектральной плотности энергетической светимости в области от 8 до $10 \mu \mathrm{m}$, является кристаллический $\mathrm{LiF}$ (рис. 7). У данного материала, нагретого до температуры $290^{\circ} \mathrm{C}$, максимум излучения находится на длине волны около $8 \mu \mathrm{m}$. Однако фтористый литий обладает рядом серьезных недостатков. В условиях повышенной влажности и высоких температур структура материала становится нестабильной, вызывая его размягчение или даже разрушение. Таким образом, использование кристаллического $\mathrm{LiF}$ не гарантирует долговременной стабильной спектральной характеристики при работе на температурах около $300^{\circ} \mathrm{C}$. Дифторид кальция $\mathrm{CaF}_{2}$ непрозрачен в длинноволновой области (более $10 \mu \mathrm{m}$ ), что не позволяет использовать этот материал в качестве излучателя, имеющего максимум спектральной плотности энергетической светимости в области от 8 до $10 \mu \mathrm{m}$. Монокристалл сапфира (оптический лейкосапфир, $\mathrm{Al}_{2} \mathrm{O}_{3}$ ) имеет отличные оптические, физические и химические свойства - является вторым по твердости материалом после алмаза, обладает высокой теплопроводностью и прозрачностью, сохраняет свои качества при высоких температурах и химически устойчив к кислотам и щелочам. Таким образом, физико-химические свойства лейкосапфира при использовании в качестве излучателя в длинноволновой ИК области обеспечивают стабильность его оптико-механических характеристик.

Для подтверждения расчетных данных произведено измерение спектральной плотности энергетической светимости сапфира при температуре $290^{\circ} \mathrm{C}$ с помощью инфракрасного фурье-спектрометра АФ-3. Результат измерения спектрофотометром спектральной плотности энергетической светимости лейкосапфира и этот же показатель, полученный расчетным путем, представлены на рис. 8.

Совместив спектральные коэффициенты пропускания интерференционных фильтров (рис. 5), отрезающего фильтра и пластины флюорита и спектральную плотность энергетической светимости сапфира при темпеpaтyре $290^{\circ} \mathrm{C}$ (по причине того, что нагрев до более высокой температуры заметно ухудшает тепловой режим газоанализатора), получим в абсолютных единицах спектральную плотность энергетической светимости отфильтрованного потока излучения, падающего на ПОИ (рис. 9). Сопоставляя рис. 6 и 9, можно констатировать практически полное подавление паразитной засветки ПОИ при использовании излучателя, имеющего максимум спектральной плотности энергетической свети-

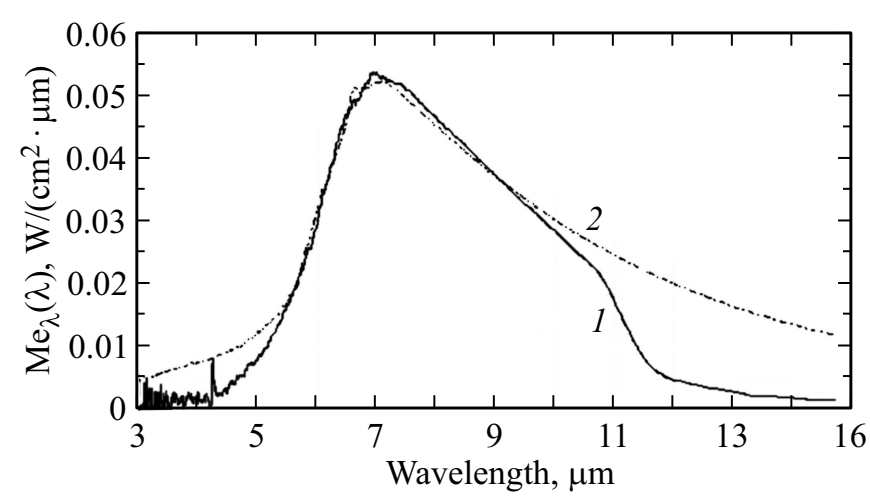

Рис. 8. Спектральная плотность энергетической светимости лейкосапфира при температуре $290^{\circ} \mathrm{C}$, полученная расчетным путем (2) и измеренная с помощью спектрофотометра (1).

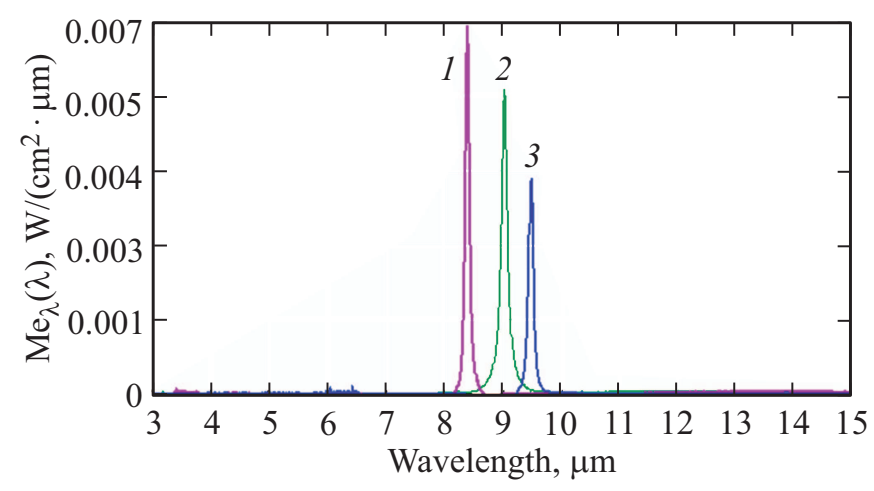

Рис. 9. Спектральная плотность энергетической светимости отфильтрованного потока излучения, падающего на ПОИ, при использовании в качестве источника излучения стержня лейкосапфира, нагретого до температуры $290^{\circ} \mathrm{C}: 1-$ фреон 114B2, 2 - фреон 22, 3 - опорный канал.

мости в области от 8 до $10 \mu \mathrm{m}$. Сигнал в области более $11 \mu \mathrm{m}$ и в области менее $7 \mu \mathrm{m}$ находится на уровне собственных шумов спектрофотометра, из чего следует, что влияние неизмеряемых компонентов должно отсутствовать.

\section{Выбор типа приемника оптического излучения}

В качестве ПОИ необходим приемник с высокой чувствительностью в спектральном диапазоне $8-10 \mu \mathrm{m}$. В работе [8] подробно рассмотрены все возможные типы ПОИ. В спектральном диапазоне $8-10 \mu \mathrm{m} \mathrm{вы-}$ сокую чувствительность имеют пироприемники, параметры которых приведены в табл. 4. Пироприемник не нуждается в источнике питания, что является его достоинством. Еще одна особенность пироприемника заключается в том, что пироэлектрический ток возникает при изменении температуры нагрева приемного элемента. Это объясняет малую инерционность пироприемника по сравнению с другими тепловыми прием- 
Таблица 4. Параметры пироэлектрических приемников излучения

\begin{tabular}{|c|c|c|c|c|c|}
\hline № & Тип, материал ППИ & $\begin{array}{c}\text { Площадь } \\
\text { чувствительного } \\
\text { элемента, } \\
\mathrm{mm} \times \mathrm{mm}\end{array}$ & $\begin{array}{c}\text { Частота модуляции, } \\
\text { Hz }\end{array}$ & $\begin{array}{c}\text { Интегральная } \\
\text { вольтовая } \\
\text { чувствительность, } \\
\text { V/W }\end{array}$ & $\begin{array}{c}\text { Порог чувствительности } \\
\text { в единичной полосе } \\
\text { частот, } \mathrm{W} / \mathrm{Hz}^{1 / 2}\end{array}$ \\
\hline 1 & $\begin{array}{l}\text { На основе керамики } \\
\text { титаната бария, [BaTiO] }\end{array}$ & $1 \times 1$ & - & 400 & $2-5 \cdot 10^{-9}$ \\
\hline 2 & МГ-30 & $1 \times 1$ & $50 \ldots 500$ & 1000 & $3 \cdot 10^{-9}$ \\
\hline 3 & МГ-32 & $1 \times 1$ & $50 \ldots 500$ & $4000 \ldots 12000$ & $0.7 \cdot 10^{-9}$ \\
\hline 4 & ПМ-3 & $\varnothing 1.5$ & $\begin{array}{c}20 \\
2\end{array}$ & $\begin{array}{l}100 \\
300\end{array}$ & $3 \cdot 10^{-9}$ \\
\hline 5 & ПМ-4 & $\varnothing 1.5$ & $\begin{array}{c}2 \\
20\end{array}$ & $\begin{array}{c}1000 \\
100\end{array}$ & $\begin{array}{l}1.5 \cdot 10^{-9} \\
1.5 \cdot 10^{-9}\end{array}$ \\
\hline 6 & ПП-02 & $\varnothing 2.6$ & $\begin{array}{c}2 \\
20\end{array}$ & $\begin{array}{c}800 \\
80\end{array}$ & $\begin{array}{l}3 \cdot 10^{-9} \\
3 \cdot 10^{-9}\end{array}$ \\
\hline 7 & ПП-03 & $2 \times 0.9$ & $\begin{array}{c}2 \\
20\end{array}$ & $\begin{array}{c}800 \\
80\end{array}$ & $\begin{array}{l}3 \cdot 10^{-9} \\
3 \cdot 10^{-9}\end{array}$ \\
\hline 8 & ПП-04 & $2 \times 2.5$ & $\begin{array}{c}2 \\
20\end{array}$ & $\begin{array}{c}1000 \\
100\end{array}$ & $\begin{array}{l}1.5 \cdot 10^{-9} \\
1.5 \cdot 10^{-9}\end{array}$ \\
\hline 9 & ПП- 82 & $2 \times 2.5$ & $\begin{array}{c}2 \\
20\end{array}$ & $\begin{array}{c}1000 \\
100\end{array}$ & $\begin{array}{l}1.5 \cdot 10^{-9} \\
1.5 \cdot 10^{-9}\end{array}$ \\
\hline
\end{tabular}

никами. Вторым достоинством пироприемника является независимость порога чувствительности от величины приемной площадки. Третьим достоинством пироприемника является тот факт, что это тепловой приемник с æ-коэффициентом использования излучения (КПД), равным 1.

В теплометрии целесообразно использовать поляризованные (монодоменные) сегнетоэлектрические кристаллы с высокой точкой Кюри (например, ниобат или танталат лития). В этих пироэлектрических материалах пирокоэффициент мало изменяется с температурой в широком температурном интервале и характеризуется временной стабильностью [9]. Из пироприемников, приведенных в табл. 4, по интегральной вольтовой чувствительности выделяется МГ-32А. По порогу чувствительности в единичной полосе частот данный пироприемник также является лучшим из представленных в табл. 4. Невозможность применения пироприемника МГ-32А обусловлена частотой модуляции излучения, которая в нашем случае составляет $0.37 \mathrm{~Hz}(2.7 \mathrm{~s})$, а рабочая частота модуляции МГ-32А составляет $50-500 \mathrm{~Hz}$. Согласно табл. 4 одинаковой чувствительностью обладают приемники ПМ-4 (не выпускается с середины 90-х годов), ПП-04 и ПП-82, которые используют в качестве чувствительного элемента кристаллы танталата лития $\left(\mathrm{LiTaO}_{3}\right)$, имеющие оптимальные техникоэкономические показатели при высоком пироэлектрическом коэффициенте. Следовательно, в качестве ПОИ целесообразно использовать ПП-04 или ПП-82.
Таблица 5. Смещение максимумов или границ пропускания в различных фильтрах

\begin{tabular}{l|c|c|c|c|c}
\hline \multirow{2}{*}{ Тип фильтра } & \multicolumn{5}{|c}{ Смещение в коротковолновую область, } \\
& \multicolumn{5}{|c}{$\lambda_{\text {max }}$ или $\lambda_{\text {кр }}$} \\
\cline { 2 - 6 } & $10^{\circ}$ & $20^{\circ}$ & $30^{\circ}$ & $40^{\circ}$ & $50^{\circ}$ \\
\hline 5ПВН2ВНВ & 0.5 & 2.0 & 4.0 & 6.0 & 10.0 \\
7ПВНВ2НВНВ & 1.0 & 3.0 & 6.0 & 11.0 & 16.0 \\
5ПВНВНВ & 1.0 & 3.0 & 7.5 & 10.0 & 13.0
\end{tabular}

\section{Описание конструкции оптического блока газоанализатора}

Если на фильтр падают лучи при углах падения, не равных $0^{\circ}$, то его максимумы и границы пропускания смещаются в коротковолновую область спектра. Зависимость такого смещения от угла падения и фильтра представлены в табл. 5. Данные, приведенные в табл. 5, определяют оптимальное значение угла падения лучей на интерференционный фильтр в диапазоне от 0 до $20^{\circ}$. Для этого необходимо обеспечить фокусировку излучения источника при помощи зеркального параболического объектива.

На основании вышеизложенного была предложена следующая оптическая схема газоанализатора (рис. 10). Конструкция представляет собой латунную трубу 4 с внутренним диаметром $18 \mathrm{~mm}$. Внутренняя полиро- 


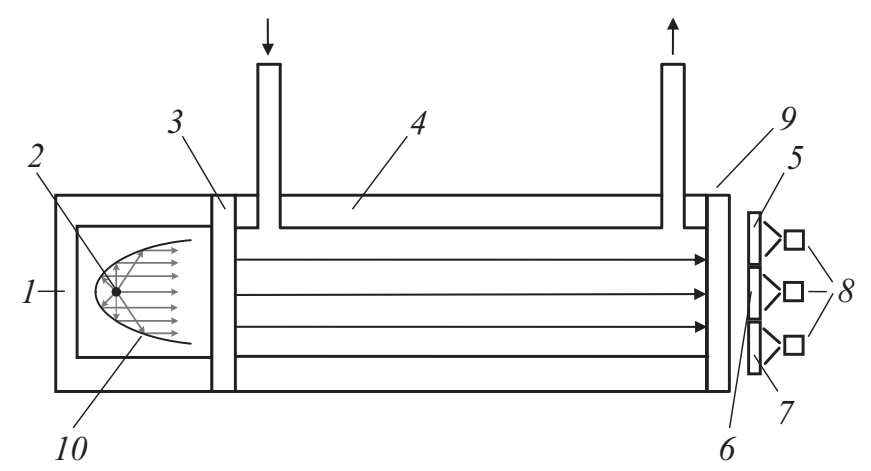

Рис. 10. Оптическая схема газоанализатора: 1 - излучатель, 2 - источник излучения, 3 - пластина просветленного германия, 4 - рабочая камера, 5- интерференционный фильтр первого канала, 6 - интерференционный фильтр второго канала, 7 - интерференционный фильтр опорного канала, $8-$ ПОИ, 9 - отрезающий фильтр+флюарит, 10 - зеркальный параболический объектив.

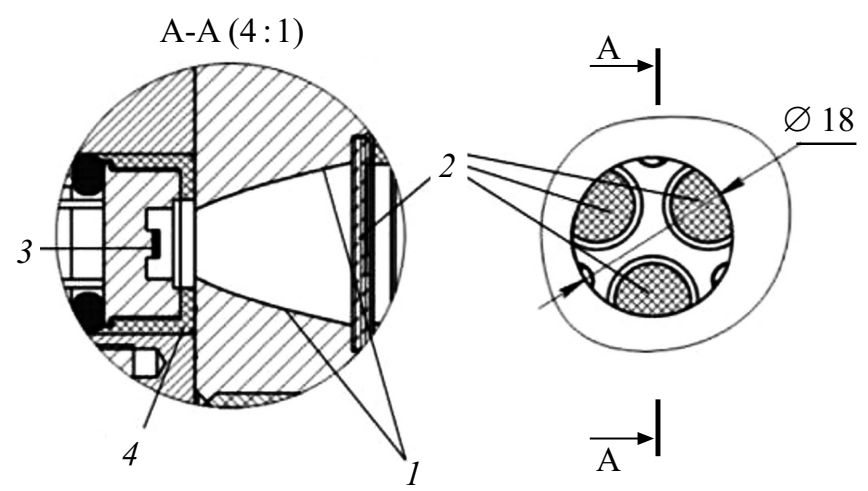

Рис. 11. Конструкция блока приемников с тремя зеркальными параболическими объективами и интерференционными фильтрами: 1 - зеркальный параболический объектив, 2 - интерференционные фильтры, 3 - чувствительная площадка приемника, 4 - пироприемник.

ванная поверхность кюветы покрывается золотом для предотвращения коррозии. С одной стороны кюветы крепится излучатель 1 , с другой стороны - блок приемников. Внутренний объем излучателя отделяется от кюветы окном 3 из просветленного германия, спектральный коэффициент пропускания просветленного германия в области 8-10 $\mathrm{m}$ составляет более $95 \%$. В качестве излучающего элемента используется стержень 2 диаметром $3 \mathrm{~mm}$ из монокристалла лейкосапфира. Стержень устанавливается в фокусе зеркального параболического объектива 10. Нагрев стержня до требуемой температуры осуществляется с помощью нагревателя, намотанного на стержень. Нагреватель изготовлен из нихромовой проволоки диаметром $0.4 \mathrm{~mm}$. Благодаря параболической поверхности зеркального объектива излучение стержня отражается от полированной поверхности объектива и образует параллельный пучок, направленный на блок приемников. Блок приемников имеет три канала измерения (рабочие 5,6 и опорный 7).

Детальный разрез одного канала блока приемника приведен на рис. 11. Приемник оптического излучения устанавливается в корпус, который рассчитан так, чтобы излучение, прошедшее через интерференционный фильтр 2, отражаясь от зеркального параболического объектива 1, сфокусировалось на приемной площадке 3 пироприемника 4.

В ходе разработки газоанализатора была выявлена необходимость введения поправок на измерение концентрации фреона в зависимости от температуры и давления. Введение поправок в программное обеспечение газоанализатора позволит компенсировать влияние температуры и давления на результаты измерения концентрации фреона.

\section{Выводы}

Благодаря применению излучателя, имеющего максимум спектральной плотности энергетической светимости в области от 8 до $10 \mu \mathrm{m}$, и системы фильтров, состоящей из узкополосных интерференционных фильтров, отрезающего фильтра и пластины флюорита, можно выделить область спектра излучения, необходимого для селективного измерения фреонов. Применение трехканальной схемы позволяет проводить измерения двух фреонов одновременно, с использованием третьего канала в качестве опорного. Кроме того, опорный и рабочие ПОИ расположены рядом в одном блоке, что исключает температурный дрейф одного приемника относительно другого.

Таким образом, за счет выбранных технических решений разработанный оптико-абсорбционный газоанализатор отличается от существующих аналогов высокой избирательностью, стабильностью показаний, малым соотношением сигнал/шум, возможностью измерять малые концентрации двух типов фреона одновременно, не требует обслуживания в межповерочный период (1 год).

\section{Конфликт интересов}

Авторы заявляют, что у них нет конфликта интересов.

\section{Список литературы}

[1] Bryant A.C.C. Refrigeration Equipment. Hoboken: Taylor\&Francis, 2012. $235 \mathrm{c}$.

[2] Wojciech D. // J. Fluorine Chem. 2012. V. 142. P. 6-13.

[3] Жерлыкина М.Н., Колосов А.И., Кузнещов С.Н., Чуйкин C.B. Моделирование концентраций холодильного агента в помещении при разгерметизации системы кондиционирования воздуха. [Электронный ресурс] Режим доступа: https://elibrary.ru/item.asp?id $=38240640$

[4] Пермяков В.Н., Махутов Н.А., Сидельников С.Н. Патент РФ № 2609185, 2017. 
[5] Васильев А.В., Гриненко Е.В., Щукин А.О., Федулина Т.Г. Инфракрасная спектроскопия органических и природных соединений. Учебное пособие. СПб.: СПбГЛТА, 2007. 54 с.

[6] Guenther B.D. Modern Optics. [Электронный pecypc] Режим доступа: https://www-oxfordscholarship-com.ezproxy.bu.edu/ view/10.1093/ acprof:oso/9780198738770.001.0001/acprof9780198738770

[7] Трубаров В.А., Снытко Ю.Н. Патент РФ № 2417354, 2011.

[8] Иианин Г.Г., Челибанов В.П. Приемники оптического излучения. Учебник. СПб.: Лань, 2014. 304 с.

[9] Поплавко Ю.М., Переверзева Л.П., Раевский И.П. Физика активных диэлектриков. Учебное пособие. Ростов-н-Дону: ЮФУ, 2009. 480 c. 